\title{
Toward a Culturally Competent Restorative Justice Practice Framework: A Focus on Asian Americans
}

\author{
Jung Jin Choi \& Margaret Severson
}

\begin{abstract}
This article suggests a culturally competent restorative justice practice framework for Asian Americans. In developing the framework, the historical development and contemporary issues of restorative justice in the West are explored, and the salient cultural traits and core elements of cultural competence with Asians and Asian Americans are examined. Tentative principles are advanced and recommendations are made for developing a culturally competent restorative justice practice framework for this cultural group, who now constitute $4.4 \%$ of the American populace, and for whom harmony in interpersonal relationships and the power of shaming are key considerations.
\end{abstract}

A s a nontraditional way of dealing with crime and addressing the particular human emotions that result from it, restorative justice approaches are widely recognized (Braithwaite, 2002; Swan, 2003; Zehr, 1990). Over the last several decades, restorative justice programs have been implemented extensively throughout North America and Europe (Umbreit \& Coates, 2000). A growing body of research (Umbreit, Coates, \& Roberts, 2001; Umbreit, Coates, \& Vos, 2002; Umbreit, Vos, \& Coates, 2005; Williams-Hayes, 2002) indicates that a restorative justice approach is especially promising in yielding participant satisfaction with the adjudication process and for redressing harm through the creation of restitution agreements.

Restorative justice, however, has received very little attention in the social work literature (Gumz, 2004; Reamer, 2004; Umbreit, 1994). Historically, the social work profession's involvement in the criminal justice system has not been pronounced, particularly because of the punitive ideology dominant in the American approach to crime prevention and response to criminal behavior (Brownell \& Roberts, 2002). Reamer points out that despite the profession's commitment to social justice as a core value of the profession, social workers have not been significantly and consistently involved in criminal justice matters. Gumz suggests that the lack of social work education's focus on the field of corrections largely results from the misalignment of values and missions between the social work profession and the justice system.

Those who have studied restorative justice recognize the compatibility of restorative justice concepts with the values long embraced by the social work profession (Gumz, 2004; Judah \& Bryant, 2004; Reamer, 2004). Within the criminal justice context, restorative justice strategies view victims as human beings rather than as objects: Victims' voices are at the fore and also at the core of the resolution process. Truth, fairness, personal and communal justice, and responsibility are some of these values, but their translation into practice, particularly when it comes to addressing the complexities of ethnic diversity in meaningful ways and applying them cross-culturally, remains a challenge to many social workers.
Indeed, scholars and practitioners in the United States struggle with the cross-cultural challenges that frequently arise in the criminal justice, restorative justice context (Umbreit \& Greenwood, 1999; Zehr, 1990). It is not difficult to imagine that context: Whether talking about racial profiling, disproportionate minority incarceration, or culturally defined responses to criminal behavior, the social science literature identifies the challenges and, at the same time, spells out their complexity (Elsner, 2006; Jacobson, 2005; National Council on Crime and Delinquency, 2007; Pewewardy \& Severson, 2003). Further, in restorative justice processes, where the victims and offenders often speak from different cultural experiences, the third-party facilitator may also represent a different culture-and, as a result, misunderstandings among all the participants become a reality (Umbreit \& Coates, 2000). Although increasing numbers of authors point to the importance of culturally competent restorative justice practice (see Jenkins, 2004, for African Americans; Raye, 2004, for Native Americans; and Umbreit \& Greenwood, 1999, for general guidelines), relatively little conceptual work has been done in a cross-cultural restorative justice context (Zehr, 1990). Although a few studies have tried to trace the restorative justice traditions in Asian cultures (see Haley, 1995, 1996), little work has been done to develop a culturally competent restorative justice practice framework for Asians and Asian Americans.

In this article, we wrestle with this work, focusing on the Asian American population. In 2001, Asian Americans comprised $4.4 \%$ of the U.S. population, and Asian-born residents accounted for one quarter of the total foreign-born population living in the United States (U.S. Census Bureau, 2003). Asian Americans collectively represent one of the fastestgrowing populations in the United States, but their experiences have generally been understudied (Fong, 1997; Kim, 1995; M. Y. Lee, 2002).

Nisbett (2003) observes that in Western cultures, conflict between individuals is handled to a substantial degree in legal confrontations, with attorneys speaking for their clients, whereas in Asian cultures, conflict is likely to be handled by intermediaries, consistent with the 
Confucian value of achieving harmony in interpersonal and social relationships. Similarly, Berg and Jaya (1993) note that in Western cultures, the presumption going into the adjudicatory process is that there is a right and a wrong-and, consequently, in achieving justice, there will be a winner and a loser. In contrast, in Asian culture, conflict resolution is more likely to mean hostility reduction, and compromise is presumed to be the likely means to that end (Nisbett). Thus, patterns of conflict resolution in Asian cultures have evidenced important aspects of restorative justice traditions, and they have shed some light on the rationale that Asian Americans might be more likely than others to want to engage in the restorative justice process.

To advance a culturally competent restorative justice paradigm for Asian Americans-particularly for those with origins in the East Asian countries of China, Japan, and Korea-this article addresses one specific question: What adaptations must be considered to apply restorative justice principles to this distinctive cultural group? We begin by exploring the development and contemporary status of restorative justiceparticularly in Europe and North America, the Western model-from a historical and social work perspective. Next, we explore the salient common cultural traits and restorative justice traditions of Asians and Asian Americans. Finally, we set out several tentative principles that are useful in moving toward a culturally competent restorative justice framework for the Asian American population.

\section{The Development and Contemporary Status of Restorative Justice Approaches}

\section{Defining Restorative Justice}

Restorative justice practice offers an opportunity to highlight the humanity of both the victim and the offender, highlighting the victim's experience within a process that is both personal and justice-oriented. The victim's voice is at the fore, and the centrality of the interpersonal dimension-that relationships among people are important, particularly the relationship between the offender and the victim-is at the heart of the process (Zehr, 1990). Crime is viewed as a violation of people and their relationships. When a crime occurs, a restorative response focuses on the harm done to victims, to communities, and to those who commit the crimes (Van Ness, 2004; Zehr, 1990, 2002), and it occurs in a participatory process where information, dialogue, and mutual agreement between victims, offenders, and communities are emphasized (Lemley, 2001). Restorative justice practice presumes that the offender has the primary responsibility to make things right-by making tangible reparations and also by repairing the relationships harmed by the offender's actions (Zehr, 2002). If and when appropriate, the relationship between the offender and the victim is restored (United Nations Office on Drugs and Crime [UNODC], 2006). In short, restorative justice means involving the victim, the offender, and the community in searching for solutions that promote repair, healing, and reconciliation (UNODC; Van Ness). In restorative justice, offenders are given an opportunity to take responsibility for their wrongdoings, and they take an active role with the victim in interpersonal problem solving (Braithwaite, 2002; Zehr, 2002).

Although there is no single right way to translate restorative justice principles into practice (Office of Juvenile Justice and Delinquency Prevention [OJJDP], 1998; Zehr, 2002), the most documented and broadly used expressions of restorative justice are found in the forms of victimoffender mediation (VOM), family group conferencing (FGC), and healing circle (HC) programs (Lightfoot \& Umbreit, 2004; Umbreit, 1998).

VOM, based on Mennonite tradition, brings the victim and offender together with a mediator in an effort to make amends for the harm inflicted and, in the process, to ask the questions often left unspoken in the traditional adversarial process (i.e., "Why me? Why did you victimize me?"). VOM emphasizes victim healing, offender accountability, and restoration of loss; in doing so, it allows for the important process of sincere apology to occur (Bradshaw \& Umbreit, 1998; Zehr, 1990).

FGC, rooted in the dispute resolution traditions of the Maori people, has been widely accepted in both New Zealand and Australia (Morris \& Maxwell, 1993). FGC brings the victim and offender-and their family members, friends, and key supports of both parties - to the table (OJJDP, 1998). Though there are FGC programs in the United States, the acceptance and growth of FGC in the United States is not as widespread as that of VOM programs (Bazemore \& Schiff, 2005; Bazemore \& Umbreit, 2004; Lemley, 2001).

Healing circles are rooted in the traditional sanctioning and healing practices of Native American cultures (Bazemore \& Umbreit, 2004; Lemley, 2001; Zehr, 1990). Healing circles bring together the victim, offender, family members, and a number of community members (such as justice and social service personnel) and interested community residents in a process of resolving the tangible and intangible harms that result from the offender's conduct (Bazemore \& Umbreit). Within the confines of the "circle," all of the victims' voices are heard so that the offender might appreciate the wide impact of his/her actions and healing can begin. Participation is voluntary and, although not highly structured, organized so that each person who wishes to talk is given the time and the respect to do so (Pranis, 2005).

Niemeyer and Schichor (1996) contrast restorative justice principles with those of the traditional retributive justice perspective because, in theory, they have the least in common. A retributive justice system emphasizes punishment and stigma: when a crime occurs, the state stands in the place of the victim and redresses the crime through the perpetrator's incapacitation or other methods of deterrence and retribution (Lemley, 2001; Zehr, 1990). Often the interests of the state take precedence to those of the victim and the sanctions have little relevance to him/her (United Nations Office for Drug Control and Crime Prevention [UNODCCP], 1999; Weitekamp, 1999). Thus, retributive justice focuses on the offender; the impact of the crime on the victim and on the community is hidden.

\section{The Evolution of Restorative Justice}

Restorative justice has its roots in ancient times, though its strategies have developed and changed over time (Nader \& Combs-Schilling, 1975). Almost all known societies used forms of restorative justice, such as restitution or compensation, when a wrong occurred (Braithwaite, 1999; Weitekamp, 1999; Zehr, 1990). In ancient societies, restitution to victims and their kin frequently took precedence over taking action against the offender, because the reestablishment of peace in the society was of the utmost importance (Weitekamp). In these early justice systems, the victim's formal and informal social network-including the family, village, and tribe-assisted in his/her recovery (UNODCCP, 1999). Over time, restitution made to victims by offenders for the wrongs done has become increasingly rare (Johnstone, 2002).

The state is the dominant power in the contemporary criminal justice system, and crime is perceived as a wrong against the state rather than as an act against an individual (Johnstone, 2002; Niemeyer \& Schichor, 1996; Weitekamp, 1999). Historically, the state's motive for assuming the victim's position in criminal matters was greed; punitive power was utilized to portray political power (Braithwaite, 1999). When the state assumed responsibility for the investigation, prosecution, and 
adjudication of the offense, the victim was afforded fewer opportunities for direct participation in the process, and the victim was essentially neglected (Weitekamp).

A growing number of states have modified their constitutions to explicitly express the state's respect for the interests of crime victims (Lightfoot \& Umbreit, 2004). The VOM model is predominant among the more than 750 restorative justice approaches used in the United States (Bazemore \& Schiff, 2005), thus it provides the context for our discussion of restorative justice.

\section{Theoretical Support for Restorative Justice}

Braithwaite (1989) proposes a theoretical foundation for restorative justice known as "reintegrative shaming," which integrates a respect for fundamental human rights, disapproval of wrongdoing, and support for reintegrating offenders into society. Braithwaite (1989) argues that "a self-fulfilling prophecy unfolds" (p. 18) because of the stigmatizing effects of labeling someone as deviant. To be effective against crime, argues Braithwaite, societies should not be tolerant of crime, but should be both "spiteful and forgiving" of it (p. 21). Thus, disapproval of the offender can be communicated within a continuum of respect (Braithwaite, 1999).

Building on Braithwaite's work, Leibrich (1996) talks of three types of shame-public humiliation, personal disgrace, and private remorseand asserts that reintegrative shaming is likely to be most effective when it results in both personal disgrace and private remorse, rather than in public humiliation only. In this understanding, two types of shaming exist on a continuum: stigmatizing on one end and reintegrative on the other (Makkai \& Braithwaite, 1994). Whereas stigmatization, a product of the retributive approaches of traditional justice systems, creates outcasts in a disrespectful and humiliating way, reintegrative shaming works in a way that respects the person as being essentially good, but demonstrates disapproval of the wrong act (Braithwaite, 1996). Braithwaite (1996) argues, "Reintegrative shaming is superior to stigmatization because it minimizes risks of pushing those shamed into criminal subcultures, and because social disapproval is more effective when embedded in relationships overwhelmingly characterized by social approval [italics added]" (p. 68). Alas, "repute in the eyes of close acquaintances matters more to people than the opinions or actions of criminal justice officials" (Braithwaite, 1996, p. 69).

The implications of reintegrative shaming theory are especially important to Asians because of the distinctive functional roles of shame, saving face, and family relations in traditional Asian culture-a culture strongly influenced by Confucianism, which emphasizes the family and community over the individual. In putting forth principles for culturally competent restorative justice practice with Asians, we hypothesize two things: (a) Because of their cultural traditions, Asian Americans may be more likely than others to want to engage in the restorative justice process; and (b) Asians Americans may perceive their experiences in VOM as humiliating and shameful, more so than would people from cultures influenced by individualism.

In the following, we review the components of culturally competent restorative justice for Asian Americans.

\section{Culturally Competent Restorative Justice}

\section{Cultural Competence in Social Work: Knowledge, Skills, and Values}

There are many rich discussions in the social work literature about the meaning and achievement of cultural competence (see Green, 1999; D.
Lum, 2007; Robbins, Chatterjee, \& Canda, 2006). Scholars have identified three important aspects of cultural competence: knowledge, skills, and values (Cross, Bazron, Dennis, \& Isaacs, 1989; Matthews, 1996; McPhatter, 1997; Weaver, 2004). Cross et al. define cultural competence as dependent on the continual acquisition of knowledge, the development of new and more advanced skills, and an ongoing self-evaluation of progress. Weaver observes that cultural competence involves recognizing a client's culture and its influence on the helping process and then being able to provide culturally congruent services. Consequently, in order to deliver culturally competent restorative justice services, practitioners need to acquire knowledge about specific populations, be equipped with the right skills to deliver the services, and be aware of their own values, biases, and beliefs (Mason, Benjamin, \& Lewis, 1996; Ronnau, 1994; Weaver).

Lee and Green (1999) make a distinction between cultural competence and culturally sensitive practice, suggesting that the latter focuses on being open to cultural differences, whereas culturally competent practice focuses on the specific cultural ways of clients. Their distinction creates an imperative for restorative justice practitioners to focus on clients' specific cultural norms and traditions as they guide the restorative work (Ragab, 1990; Walton \& Abo-El-Nasr, 1988). To achieve any measure of cultural competence, practitioners must understand and accept diverse cultural norms and practices as being valid (Robbins et al., 2006) and recognize the power of cultural scripts in shaping client behavior and values and in guiding the delivery of services to clients (Pabon, 1998).

The concept of authentization, coined by Walton and Abo-El-Nasr (1988, p. 136) and further elaborated by Ragab (1990) is especially relevant in understanding cultural norms, practices, and scripts. Authentization requires practitioners to go "back to the roots to seek direction" (Ragab, 1990, p. 43) for cultural competence. Kee (2004) understands this concept as "a search from within" (p. 336) a client's own culture. The restorative justice practitioner must refocus on the worldviews and cultures of the local people when practicing in a culturally competent manner. Thus, a culturally competent approach for Asian Americans should redirect practitioners toward acquiring a rich understanding of Asian American cultural norms and traditions.

\section{The East in the West: Culture and Asian Americans}

The population of Asian Americans referenced-including people of Chinese, Japanese, and Korean origins - reflects a variety of educational, political, socioeconomic, and religious backgrounds as well as different migration histories (E. Lee, 1997; U.S. Census Bureau, 2003). While three different subgroups of Asian Americans exist-including Southeast Asians, Asian Indians, and other Asians-there is a great diversity within the Asian populations (Morelli, 2005). As Berg and Jaya (1993, p. 31) assert, it is impossible to generalize characteristics of Asian American families because there is no typical Asian American family. At the same time, there are cultural values that distinguish Asian Americans from other Americans (Uba, 1994). While singularly categorizing these disparate groups of Asian Americans can partly hide individual differences and lead to the formation of stereotypes, it is important to the development of cultural competency and to the growth in one's understanding of Asian Americans to see Asian Americans as one and as many-to appreciate the generalizations and to commit to developing a further understanding and respect for the differences that exist among people.

Asian Americans infrequently use social services, receive poorer quality of care when they do, and have a higher proportion of unmet 
needs (Morelli, 2005; U.S. Department of Health and Human Services, 1999). As the fastest-growing ethnic population in the United States, Asian Americans are desperate for services designed and delivered in a way that is consistent with the values of their unique cultures. These values include strong mutual support; interdependence among family members; strong hierarchical, stable patterns of family relations with a strong sense of obligation; a strong family influence for matters outside of the family; and problem solving that occurs within the family rather than with reliance on professional helpers (Green, 1999).

S. X. Zhang (1995) measured shaming in different ethnic contexts and found that for most Asian parents, the arrest of a child is not only considered "an embarrassment for the family, but also an indication of failure in parental efforts to steer the child in the right direction" (p. 259). The study interviewers also observed that many Asian mothers wept during the interviews. They also expressed remorse over their children's behavior that caused trouble in society. Many parents considered the punishment such as the fines and community service "as a payback to society" (p. 260). In contrast, in the same study, many African American parents viewed an arrest as another confrontational incident with the justice system directed more at external and social factors. Another significant finding of the study was that new immigrant Asian parents with delinquent children born abroad were much more likely to use shaming than were other parents who had assimilated into the Western culture.

Bae $(1996,2000)$ investigated the possibility of implementing restorative justice strategies in the Korean context. The researcher asked several questions to Korean juvenile offenders, including "For whom do you feel the most sorry right after your offense?" Most of the juvenile offenders responded that they felt sorry for their parents, because the parents were doing their best and the juveniles were failing to meet their parents' expectations. Only a few juvenile offenders answered that they felt sorry for their victims. In attempting to explain these answers, Bae points out the unique family-oriented culture of Koreans.

Nisbett (2003) suggests that there are differences in the nature of the Asian thought process, differences that make Asians distinctive from people of other cultures. At least two salient cultural traits are both valued and socially functional when it comes to understanding Asian Americans: Confucian culture and shame (Berg \& Jaya, 1993; Green, 1999; Kim, 1995; E. Lee, 1997; M. Y. Lee, 2002; Morelli, 2005; Tsukuda, 1999; Uba, 1994; Yip, 2005).

\section{Confucian Culture}

Confucian philosophy has been at the core of Asian survival through their cultural history (Morelli, 2005). Canda (2002) defines Confucian philosophy as "a system of social ethics and ritual forms based upon a holistic cosmology that promoted harmony between heaven, earth, and humanity" (p. 3). Yao (2000) explains that Confucianism is more than the values of a group of people; it contains a sociopolitical program, an ethical system, and a religious tradition. It functions as an underlying ideology and a guiding principle that reflects the Chinese attitude toward life and the world-but Confucianism also has spread to Korea and Japan, flourishing in both countries in distinctive ways (Canda; Yao). Consistent with the influence of Confucianism, the value of harmony in interpersonal relationships is important (Yao).

The influence of Confucianism on Asians is seen in their being more likely to have a family orientation that causes individuals to subordinate their personal goals, interests, and welfare to that of their families' welfare (Yang, 1995). Similarly, Yip (2005) notes that Asian cultures place an emphasis on collectivism and familism, which cre- ates interdependence rather than independence in social relationships. Nisbett (2003) cites Henry Rosemont, who has written on individuals in a Confucian culture:

I am the totality of roles I live in relation to specific others...Taken collectively, they weave, for each of us, a unique pattern of personal identity, such that if some of my roles change, the others will of necessity change also, literally making me a different person. (p. 5)

This social weaving of relationships is especially exemplified in filial piety, defined as duty to one's parents: unquestioning loyalty, obedience, care, concern, and anticipation of parental needs (Chan, cited in Morelli, 2005). Therefore, family members are responsible for one another (Kim, 1995).

Several studies (Chang, 1996; Huang et al., 2004; Leong, 1986) report that some members of Asian American populations are less assertive and more submissive than those in non-Asian American populations. In particular, Huang et al. note that this demeanor, consistent with Asian values, may result from the struggle for harmony and, consequently, result in discouraging individualism. In their study, however, Sue, Ino, and Sue (1983) found that their Chinese American participants were just as assertive as Caucasian participants in certain situations, such as in informal settings or when with members of their own ethnic background. In contrast, the participants tended to be nonassertive when with authority figures or in public settings where non-Asian American individuals were present. Such findings have implications for the negotiations that go on within the restorative justice context, and they will be addressed further in this article. Still, as Leong highlights, the degree of acculturation between earlier and later generations of Asians should be considered, because later generations are more likely to internalize the mainstream culture of America, as S. X. Zhang (1995) also discussed earlier.

\section{Shame}

Given the importance of collective existence and family lineage in traditional Asian cultures, many Asians avoid using formal social services for fear of shaming the family name and/or losing face (I. Lee, 2005; M. Y. Lee, 2002; J. Lum, 1998). The behavior of individual members of an Asian family reflects on the whole family; thus, the avoidance of shame is the principal tool used to control the behavior of family members in this culture (Kim, 1995). Berg and Jaya (1993) observe that interpersonal relationships among Asians are based on shame more than guilt. For instance, failure in school, disobedience, and juvenile delinquency are sources of great shame for the family. In explaining the shame in Asian domestic violence situations, M. Y. Lee (2002) reveals that disclosing violence may have different cultural meanings. On one hand, it can be interpreted as a demonstration of courage or a show of personal strength; on the other hand, it "may also mean exposing weakness to outsiders, shaming the family name, violating the virtues of perseverance and endurance, challenging male supremacy, and bringing disruption to the family" (M. Y. Lee, 2002, p. 474). Consequently, Chan (cited in Morelli, 2005) notes that public disclosure of family problems, although it is to provide information to a helping professional, is still very difficult for many Asian families, because it may be considered a betrayal of family trust as well as a disgrace of family honor.

\section{Restorative Justice in the Asian Cultures}

Haley (1995) asserts that restorative justice programs in North America and Europe do not reflect a global experience. Many scholars have 
found that the restorative elements of Japanese social control are both influential and sophisticated (Braithwaite, 2002; Haley, 1995, 1996; Zehr, 1990). Kawashima (cited in Stookey, 1975) reports that the Japanese system of restitution is almost entirely settled by extrajudicial agreements; the Japanese prefer extralegal decisions because they do not focus on the conflict, but rather on the negotiating process. Haley $(1995,1996)$ observes that Japan has been successful in significantly reducing crime during the 1980s and 1990s because of the communitarian orientation of Japanese culture and because of their restorative model of criminal justice. Since effective crime control requires reintegration of the offender into the community, communitarian societies can be more effective in crime reduction and prevention (Braithwaite, 1989). In Japanese culture, when offenders confess, they or their families tend to approach victims to make redress and seek forgiveness. Typically, victims accept the offerings and offer pardon, which is often communicated formally to prosecutors and courts (Haley, 1996). Zehr (1990, p. 218) identifies the unique variables of the Japanese restorative justice model: (a) the offender's willingness to acknowledge guilt, (b) an expression of remorse and making compensation to the victim, and (c) the victim's willingness to receive compensation and to pardon.

The Chinese approach to restorative justice also has drawn attention (Braithwaite, 2002; Zehr, 1990), particularly the bang jiao program (Lu, 1999; X. Zhang, 2004). Lu defines bang jiao as "the efforts by social groups including private and state institutions, neighborhood organizations, schools, and workplaces to help correct individuals' deviant behaviors and thoughts, and to help them come to terms with social norms and be reintegrated back into the society" (p. 116). In bang jiao, the participation of local community members is important to educate former offenders during their reintegration process and to keep them from recidivating (X. Zhang, 2004). Neighborhood bang jiao-comprised of groups of neighborhood committee members such as community police officers, teachers, coworkers, family members, and community activists-provides supervision and assistance to former offenders $(\mathrm{Lu})$. Lu identifies three major components in bang jiao reintegration activities: (a) decertifying offenders' deviant status; (b) facilitating offenders in starting a new life; and (c) engaging offenders in various community activities and services, such as cleaning the streets and providing free repairs.

The restorative justice traditions in Asian cultures evidence the unique locality and indigenousness seen in the origins of Western restorative justice practices such as VOM. These two examples from Japan and China provide ideas about culturally acceptable methods used to rehabilitate the offender. However, both fall short of fully integrating the victim into the restorative justice process, whereas a focus on the victim has been a key in the American application of restorative justice methods.

\section{Toward a Culturally Competent Restorative Justice Framework}

The recent development of restorative justice in North America is an example of a majority culture being influenced by local restorative justice traditions (Barron, 1998). Swan (2003) speculates that restorative justice in the future will likely emerge from other Westernized interpretations of indigenous theory and practice. To move toward a culturally competent restorative justice for Asians and Asian Americans, practitioners need to begin and end the conversation with principles based on cultural traditions. Applying a Westernized restorative justice framework to Asian Americans without gauging the historical and present sociocultural context is an error, not only because cultural traditions and mores should be honored, but also because one risks misapplying the principles themselves (Zehr, 1990). Practitioners must understand that the principles proposed here allow for flexibility; they account for the uniqueness of individual expression and the recognition that there is no fixed Asian American culture.

Umbreit and Coates (2000) suggest that restorative justice practitioners working with participants from multicultural backgrounds must (a) know themselves, (b) know the participants, and (c) prepare the participants. They assert that opportunities for restorative justice can only be enhanced when those who work in justice programs take the time and expend the energy to understand cultural differences and related communication problems. In their restorative justice practice, practitioners must study the cultures at the table, be aware of their own values and biases, and reflect upon their own behaviors and communication styles. Armed with the relevant cultural knowledge, practitioners will be better prepared to work with diverse groups of participants.

In the restorative justice context, the salient cross-cultural traits of Asians and Asian Americans include (a) the value of harmony in interpersonal and social relationships based on Confucian culture and (b) the fear of shaming the family name. While retributive justice schemes may lead to cycles of vengeance and violence, a restorative response can lead to cycles of balance and harmony (Zehr, 2002). Zehr argues that by emphasizing the importance of interconnectivity in restorative justice, "we are all connected to each other and to the larger world through a web of relationships" (p. 35). Drawing upon the common cultural values of harmony and interdependence in restorative justice and Asian cultures, Asian Americans can begin to restore interpersonal relationships, heal injuries, and create and make use of opportunities for offenders to take responsibility for their crimes.

Shame has different meanings and significance in different cultures. In some European cultures, shame is more about the individual person, but with Asians and Asian Americans, shame is principally about both the individual and the family (Braithwaite, 1999). Thus, applying the Western model of VOM to Asian Americans should be done with this knowledge in mind. When the families of both the victim and offender are invited to a VOM, it may be experienced as a source of shaming the family name-so for many Asian Americans, it also means a loss of face. As S. X. Zhang (1995) observes, Asian parents may interpret the circumstances that bring the child into the VOM process as their own personal parenting failure. Also, it may be difficult for Asian Americans, as victims of crime, to witness a moment of authentic shame and remorse from the offender with a different ethnic background, because in individual Western law, guilt is individual and the individual concept of guilt ignores the importance of context (Braithwaite, 1999; Zehr, 1990). In a culturally competent restorative justice model for Asian Americans, care must be taken to understand the meaning of shame from both the offender's and family's perspectives, so that the process does not alienate the family or end in a disrespectful and humiliating experience for them.

In their family lives, in order to ensure harmonious social interaction, Asians tend to follow intricate rules of communication-based on social status, age, sex, education, occupation, family background, and marital status - that determine what is communicated and how it is communicated (Chan, cited in Morelli, 2005). Delivering an apology is an example of a culture-bound communication event (I. Lee, 2005). In Asian cultures, influenced by Confucianism, when one's action results in another's injury, an apology is expected. In the United States, a system of allegations and denials is integral to the legal culture, the culture 
in which many restorative justice practitioners are trained and the system that often serves as the catalyst for a VOM referral. In reality, some VOM processes occur within the criminal justice system (Bazemore \& Schiff, 2005; Bonta, Jesseman, Rugge, \& Cormier, 2006). Consequently, an Asian offender or his/her parent may be seen as being overly apologetic, and such apologies may be interpreted as admissions of guilt that may lead to more severe legal repercussions.

Umbreit (1995) observes that if one or both VOM participants are uncomfortable with talking face to face, one of the parties can abuse the other by intimidation or aggression. We think that Asian Americans in VOM situations may be at particular risk to face such difficulties. Thus, to develop culturally competent restorative communication skills with Asian Americans, we think that Morelli's (2005) suggestions are helpful for practitioners, especially those with Anglo American cultural backgrounds. Practitioners should do the following:

1. Observe nonverbal and indirect communication carefully, because those forms of communication convey more information than verbal communication.

2. Listen more than speak.

3. Be aware of one's own feelings about being silent and how those feelings might be communicated nonverbally.

4. Be patient as well as alert.

5. Assess the language proficiency of the participants, given the complicated and difficult nature of VOM conversations. (Morelli, 2005)

6. In addition, practitioners must provide a trained interpreter for Asian American participants who have limited secondlanguage skills.

\section{Implications for Practice}

Our review of the historical development of restorative justice in Western countries reveals that its roots are as old as human history (Johnstone, 2002; Weitekamp, 1999). The recent development of restorative justice in the West is one in which the importance of bringing forth the local culture and justice traditions and adapting them to the American justice system must be underscored. To construct a culturally competent restorative justice practice for Asian Americans, it is necessary for practitioners to learn about this population's rich cultural and justice traditions; these indigenous traditions should resonate in contemporary restorative justice practice approaches. Also, the danger of oversimplifying the Asian and Asian American cultures should not be taken lightly. Practitioners must be wary of stereotyping; not all traits are bound by culture, and thus not all of the members of the population will share them. The dialogue on restorative justice and its potential as a culturally competent approach with certain cultural populations must continue and be used as the springboard to promote the evolution of restorative justice approaches in the United States and elsewhere. Practitioners who facilitate restorative justice strategies with Asian Americans must provide informed and quality services, and they can only do so with enhanced cultural competence (Weaver, 1999).

Restorative justice has a unique place in the larger criminal justice realm. Its compatibility with social work values is clear; social justice, the support and maintenance of personal dignity, and the importance of interpersonal relationships and professional competence are at the foundation of social work and restorative justice practice. The framework we have proposed suggests a reflexive process: A collaborative pursuit of knowledge and understanding that occurs between practitio- ners and researchers - and out of which a dynamic framework for more culturally competent practice with the Asian American populationswill emerge. Importantly, this collaboration will promote cross-cultural exchange and learning between different cultures for the mutual benefit of all (Canda, 2002). To move toward culturally competent restorative justice for Asian Americans, we propose these practice guidelines:

Recognize needs. Particularly the participants' personal needs and the social imperative for culturally competent restorative justice practice with Asian Americans.

Consider limits. Critically consider and acknowledge the limits of the Western restorative justice model.

Be aware. Assess one's own values and biases; embrace the personal and social challenges inherent in exposure to new cultures as living representations of justice.

Understand. Know the cultural roots and implications of shaming and the nuances of family communication.

Increase knowledge. This includes Asian Americans' salient cultural traits such as the importance of family, the concept and meaning of shame, and their restorative justice traditions.

Be wary of stereotyping. Not all traits apply to all Asian Americans.

Provide feedback. Voice and document what is learned in practice, and collaborate with researchers to modify the restorative justice models to ensure their cultural sensitivity.

\section{Conclusion}

To move toward culturally competent restorative justice, we believe that one must be highly sensitive to the cultural traditions and norms and ways of being that may influence the restorative justice process in both good and bad ways. Morris (2002) comments that we may need more time to translate the critical values that are part and parcel of restorative justice theory into good modern-day restorative justice practice. In taking the first step at opening the dialogue, we begin by building on theory in the effort to achieve culturally competent restorative justice practices with Asian Americans.

\section{References}

Bae, I. H. (1996). 소년보호관찰 프로그램의 효과적 연구방안에 관한 연구 [A study on effective probation for juvenile offenders.] 교정연구 [Correction Study], $6,245-278$.

Bae, I. H. (2000). 비행청소년을 위한 범죄피해자, 가해자, 중재 프로그램 실천 가능성, [A study on the possibility of applying the idea of victim offender mediation to juvenile offenders]. 교정연구 [Correction Study], 11, 181-221.

Barron, M. H. (1998). Finding our way: Paths to justice reform in an aboriginal community. Unpublished doctoral dissertation, McMaster University, Hamilton, Ontario.

Bazemore, G., \& Schiff, M. (2005). Juvenile justice reform and restorative justice: Building theory and policy from practice. Portland, OR: Willan.

Bazemore, G., \& Umbreit, M. S. (2004). Balanced and restorative justice: Prospects for juvenile justice in the 21st century. In A. R. Roberts (Ed.), Juvenile justice sourcebook: Past, present, and future (pp. 467-510). New York: Oxford University Press.

Berg, I. K., \& Jaya, A. (1993). Different and same: Family therapy with AsianAmerican families. Journal of Marital \& Family Therapy, 19(1), 31-38.

Bonta, J., Jesseman, R., Rugge, T., \& Cormier, R. (2006). Restorative justice and recidivism: Promises made, promises kept? In D. Sullivan \& L. Tifft (Eds.), Handbook of restorative justice (pp. 108-120). New York: Routledge.

Bradshaw, W., \& Umbreit, M. S. (1998). Crime victims meet juvenile offenders: Contributing factors to victim satisfaction with mediated dialogue. Juvenile \& Family Court Journal, 49(3), 17-25.

Braithwaite, J. (1989). Crime, shame and reintegration. Cambridge, UK: Cambridge University Press.

Braithwaite, J. (1996). Restorative justice and a better future. Dalhousie Review, 76(1), 9-32.

Braithwaite, J. (1999). Restorative justice: Assessing optimistic and pessimistic accounts. Crime and Justice, 25(1), 1-104. 
Braithwaite, J. (2002). Restorative justice \& responsive regulation. New York: Oxford University Press.

Brownell, P., \& Roberts, A. R. (2002). A century of social work in criminal justice and correctional settings. Journal of Offender Rehabilitation, 35(2), 1-17.

Canda, E. R. (2002). Toward spiritually sensitive social work scholarship: Insights from classical Confucianism. Electronic Journal of Social Work, 1(1), 1-23.

Chang, E. C. (1996). Cultural differences in optimism, pessimism, and coping: Predictors of subsequent adjustment in Asian American and Caucasian American college students. Journal of Counseling Psychology, 43, 113-123.

Cross, T. L., Bazron, B. J., Dennis, K. W., \& Isaacs, M. R. (1989). Towards a culturally competent system of care. Washington, DC: Georgetown University Child Development Center.

Elsner, A. (2006). Gates of injustice. Upper Saddle River, NJ: Pearson Education.

Fong, L. Y. S. (1997). Asian-American women: An understudied minority. Journal of Sociology and Social Welfare, 21(1), 91-111.

Green, J. W. (1999). Cultural awareness in the human services: A multi-ethnic approach. Boston: Allyn \& Bacon.

Gumz, E. J. (2004). American social work, corrections and restorative justice: An appraisal. International Journal of Offender Therapy and Comparative Criminology, 48(4), 449-460.

Haley, J. O. (1995). Victim-offender mediation: Lessons from the Japanese experience. Mediation Quarterly, 12(3), 233-248.

Haley, J. O. (1996). Crime prevention through restorative justice: Lessons from Japan. In B. Galaway \& J. Hudson (Eds.), Restorative justice: International perspectives (pp. 349-371). Monsey, NY: Criminal Justice Press.

Huang, W., DeLambo, D. A., Kot, R., Ito, I., Long, H., \& Dunn, K. (2004). Self-advocacy skills in Asian American parents of children with developmental disabilities: A pilot study. Journal of Ethnic \& Cultural Diversity in Social Work, 13(1), 1-18.

Jacobson, M. (2005). Downsizing prisons: How to reduce crime and end mass incarceration. New York: New York University Press.

Jenkins, M. (2004). How do culture, class, and gender affect the practice of restorative justice? (Part 1). In H. Zehr \& B. Toews (Eds.), Critical issues in restorative justice (pp. 315-328). Monsey, NY: Criminal Justice Press.

Johnstone, G. (2002). Restorative justice: Ideas, values, debates. Portland, OR: Willan.

Judah, E. H., \& Bryant, M. (Eds.). (2004). Rethinking criminal justice: Retribution vs. restoration. Binghamton, NY: Haworth Press.

Kee, L. H. (2004). The search from within: Research issues in relation to developing culturally appropriate social work practice. International Social Work, 47(3), 336-345.

Kim, Y. O. (1995). Cultural pluralism and Asian-Americans: Culturally sensitive social work practice. International Social Work, 38, 69-78.

Lee, E. (1997). Working with Asian Americans: A guide for clinicians. New York: Guilford Press.

Lee, I. (2005). The law and culture of the apology in Korean dispute settlement (with Japan and the United States in mind). Michigan Journal of International Law, 27(1), 1-53.

Lee, M. Y. (2002). Asian battered women: Assessment and treatment. In A. R. Roberts (Ed.), Handbook of domestic violence intervention strategies: Policies, programs, and legal remedies (pp. 472-482). New York: Oxford University Press.

Lee, M. Y., \& Green, G. J. (1999). A social constructive framework for integrating crosscultural issues in teaching social work. Social Work Education, 35(1), 20-30.

Leibrich, J. (1996). The role of shame in going straight: A study of former offenders. In B. Galaway \& J. Hudson (Eds.), Restorative justice: International perspectives (pp. 283-302). Monsey, NY: Criminal Justice Press.

Lemley, E. C. (2001). Designing restorative justice policy: An analytical perspective. Criminal Justice Policy Review, 12(1), 43-65.

Leong, F. T. L. (1986). Counseling and psychotherapy with Asian-Americans: Review of the literature. Journal of Counseling Psychology, 33, 196-206.

Lightfoot, E., \& Umbreit, M. S. (2004). An analysis of state statutory provisions for victim-offender mediation. Criminal Justice Policy Review, 15(4), 418-436.

$\mathrm{Lu}, \mathrm{H}$. (1999). Bang jiao and reintegrative shaming in China’s urban neighborhoods. International Journal of Comparative and Applied Criminal Justice, 23(1), 115-125.

Lum, D. (2007). Culturally competent practice: A framework for understanding diverse groups and justice issues. Belmont, CA: Thomson Brooks/Cole.

Lum, J. (1998). Family violence. In L. C. Lee \& N. W. S. Zane (Eds.), Handbook of Asian American psychology (pp. 505-526). Thousand Oaks, CA: Sage.

Makkai, T., \& Braithwaite, J. (1994). Reintegrative shaming and compliance with regulatory standards. Criminology, 32(3), 361-385.

Mason, J. L., Benjamin, M. P., \& Lewis, S. (1996). The cultural competence model: Implications for child and family mental health services. In C. A. Heflinger \& C. T. Nixon (Eds.), Families and the mental health system for children and adolescents (pp. 165-190). Thousand Oaks, CA: Sage.

Matthews, L. (1996). Culturally competent models in human service organizations. Journal of Multicultural Social Work, 4(4), 131-135.
McPhatter, A. R. (1997). Cultural competence in child welfare: What is it? How do we achieve it? What happens without it? Child Welfare, 76, 255-278.

Morelli, P. T. T. (2005). Social work practice with Asian Americans. In D. Lum (Ed.), Cultural competence, practice stages, and client systems: A case study approach (pp. 112-145). Belmont, CA: Brooks/Cole.

Morris, A. (2002). Critiquing the critics: A brief response to critics of restorative justice. British Journal of Criminology, 42, 596-615.

Morris, A., \& Maxwell, G. M. (1993). Juvenile justice in New Zealand: A new paradigm. The Australian \& New Zealand Journal of Criminology, 26(1), 72-90.

Nader, L., \& Combs-Schilling, E. (1975). Restitution in cross-cultural perspective. In J. Hudson \& B. Galaway (Eds.), Restitution in criminal justice. Lexington, MA: Lexington Books.

National Council on Crime and Delinquency. (2007). And justice for some: Differential treatment of youth of color in the justice system. Oakland, CA: Author.

Niemeyer, M., \& Schichor, D. (1996). A preliminary study of a large victim/offender reconciliation program. Federal Probation, 60(3), 30-34.

Nisbett, R. E. (2003). The geography of thought: How Asians and Westerners think differently... and why. New York: Free Press.

Office of Juvenile Justice and Delinquency Prevention. (1998). Guide for implementing the balanced and restorative justice model. Washington, DC: U.S. Dept. of Justice.

Pabon, E. (1998). Providing culturally competent juvenile justice services to the Latino community. Professional Development: The International Journal of Continuing Social Work, 1(1), 38-46.

Pewewardy, N., \& Severson, M. (2003). A threat to liberty: White privilege and disproportionate minority incarceration. Journal of Progressive Human Services, 14(2), 53-74.

Pranis, K. (2005). The little book of circle processes. Intercourse, PA: Good Books.

Ragab, I. (1990). How social work can take root in developing countries. Social Development Issues, 12(3), 38-51.

Raye, B. (2004). How do culture, class and gender affect the practice of restorative justice? (Part 2). In H. Zehr \& B. Toews (Eds.), Critical issues in restorative justice (pp. 329-340). Monsey, NY: Criminal Justice Press.

Reamer, F. G. (2004). Social work and criminal justice: The uneasy alliance. Journal of Religion \& Spirituality in Social Work, 23(1/2), 213-231.

Robbins, S. P., Chatterjee, P., \& Canda, E. R. (2006). Contemporary human behavior theory: A critical perspective for social work (2nd ed.). Boston: Allyn \& Bacon.

Ronnau, J. P. (1994). Teaching cultural competence: Practical ideas for social work educators. Journal of Multicultural Social Work, 3(1), 29-42.

Stookey, J. A. (1975). The victim's perspective on American criminal justice. In J. Hudson \& B. Galaway (Eds.), Restitution in criminal justice. Lexington, MA: Lexington Books.

Sue, D., Ino, S., \& Sue, D. M. (1983). Nonassertiveness of Asian Americans: An inaccurate assumption? Journal of Counseling Psychology, 30(4), 581-588.

Swan, R. S. (2003). On the rocky road to "restoring" justice: The restorative justice movement in the United States. Unpublished doctoral dissertation, University of California, Irvine, CA.

Tsukuda, G. (1999). Commentary on the paper by Ino and Glicken, "Treating Asian American clients in crisis: A collectivist approach." Smith College Studies in Social Work, 69(3), 541-546.

Uba, L. (1994). Asian Americans: Personality patterns, identity, and mental health. New York: Guilford Press.

Umbreit, M. S. (1994). Crime victims confront their offenders: The impact of a Minneapolis mediation program. Research on Social Work Practice, 4(4), 436-447.

Umbreit, M. S. (1995). Mediating interpersonal conflicts: Approaches to peacemaking for families, schools, workplaces, and communities. Eugene, OR: Wipf and Stock.

Umbreit, M. S. (1998). Restorative justice through victim-offender mediation: A multi-site assessment. Western Criminology Review, 1(1). Retrieved September 2, 2008, from http://wcr.sonoma.edu/v1n1/umbreit.html

Umbreit, M. S., \& Coates, R. B. (2000). Multicultural implications of restorative justice: Potential pitfalls and dangers. Washington, DC: Office for Victims of Crime.

Umbreit, M. S., Coates, R. B., \& Roberts, A. W. (2001). The impact of victimoffender mediation: A cross-national perspective. Mediation Quarterly, 17(3), 215-229.

Umbreit, M. S., Coates, R. B., \& Vos, B. (2002). The impact of restorative justice conferencing: A multi-national perspective. British Journal of Community Justice, 1(2), 21-48.

Umbreit, M. S., \& Greenwood, J. (1999). National survey of victim-offender mediation programs in the United States. Mediation Quarterly, 16(3), 235-251.

Umbreit, M. S., Vos, B., \& Coates, R. B. (2005). Restorative justice dialogue: A review of evidence-based practice. Offender Programs Report, 9(4), 49-64.

United Nations Office for Drugs and Crime (UNODC). (2006). Handbook on restorative justice programmes. New York: United Nations. 
United Nations Office for Drug Control and Crime Prevention (UNODCCP). (1999). Handbook on justice for victims. New York: Centre for International Crime Prevention.

U.S. Census Bureau. (2003). Asian Pacific American heritage month: May 2003. Retrieved April 5, 2008, from http://www.census.gov/Press-Release/ www/2003/cb03-ff05.html

U.S. Department of Health and Human Services. (1999). Mental health: Culture, race and ethnicity. Rockville, MD: Author.

Van Ness, D. W. (2004). Justice that restores: From impersonal to personal justice. Journal of Religion \& Spirituality in Social Work, 23(1/2), 93-109.

Walton, R. G., \& Abo-El-Nasr, M. M. (1988). Indigenization and authentization in terms of social work in Egypt. International Social Work, 31(1), 135-144.

Weaver, H. N. (1999). Indigenous people and the social work profession: Defining culturally competent services. Social Work, 44(3), 217-225.

Weaver, H. N. (2004). The elements of cultural competence: Applications with Native American clients. Journal of Ethnic \& Cultural Diversity in Social Work, 13(1), 19-35.

Weitekamp, E. (1999). The history of restorative justice. In G. Bazemore \& L. Walgrave (Eds.), Restorative juvenile justice: Repairing the harm of youth crime. Monsey, NY: Criminal Justice Press.

Williams-Hayes, M. M. (2002). The effectiveness of victim-offender mediation and family group conferencing: A meta-analysis. Unpublished doctoral dissertation, University of Tennessee, Knoxville, TN.

Yang, K. S. (1995). Chinese social orientation: An integrative analysis. In T. Y. Lin, W. S. Tseng, \& E. K. Yeh (Eds.), Chinese societies and mental health. Hong Kong: Oxford University Press.
Yao, X. (2000). An introduction to Confucianism. Cambridge, UK: Cambridge University Press.

Yip, K. S. (2005). A dynamic Asian response to globalization in cross-cultural social work. International Social Work, 48(5), 593-607.

Zhang, S. X. (1995). Measuring shaming in an ethnic context. The British Journal of Criminology, 35(2), 248-262.

Zhang, X. (2004). A restorative justice audit of the Chinese criminal justice system. Unpublished master's thesis, London School of Economics and Political Science, London, UK.

Zehr, H. (1990). Changing lenses. Scottdale, PA: Herald Press.

Zehr, H. (2002). The little book of restorative justice. Intercourse, PA: Good Books.

Jung Jin Choi, PhD, MSW, is assistant professor, School of Social Work, Florida Atlantic University. Margaret Severson, JD, MSW, is associate professor, School of Social Welfare, University of Kansas. Correspondence regarding this article can be sent to the first author at jchoi3@fau.edu or 777 Glades Road, SO 284, Boca Raton, FL 33431-0991.

Manuscript received: April 15, 2008

Revised: July 29, 2008

Accepted: July 31, 2008

The Severson Center presents:

\section{Scanning The Horizons 2009-2010: Top Five Trends}

For the first time, the trends and impactsand opportunities linked to them-within the report have been identified by both the Alliance National Trend Advisory Committee and faculty from the University of Notre Dame, Mendoza College of Business.
To help human service providers develop targeted plans and programs, Scanning the Horizons 2009-2010: Top Five Trends provides an overview of top factors, issues and uncertainties affecting society and the nonprofit field. To purchase a copy, visit alliancetrends.org

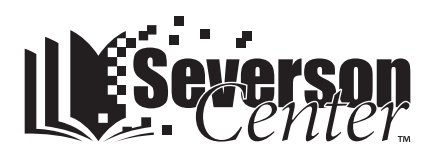

A Severson Select Resource

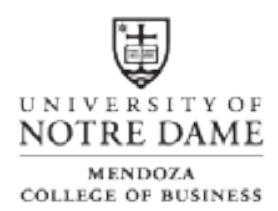

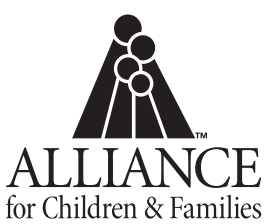

